\title{
Correction to: Further Aspects of Hair Transplantation
}

\section{Correction to: Chapter 6 in: R. P. Azar, FUE Hair Transplantation, https://doi.org/10.1007/978-3-319-75901-2_6}

This book was inadvertently published without Ludger Mentrup's name as one of the authors in Chapter 6. This has now been amended throughout the book mentioning Ludger Mentrup as a co-author in chapter 6.

The updated online version of the chapter can be found at https://doi.org/10.1007/978-3-319-75901-2_6

R. P. Azar ( $\square)$

Zentrum für Moderne Haartransplantation, Berlin, Germany

e-mail: info@ifue-haartransplantation.de

L. Mentrup

Wilhelmshöher Str. 84, 60389 Frankfurt, Germany

e-mail: info@alopezie.de 